PPPL-3465

PPPL-3465

UC-70

Stability and Transport in Compact Quasi-Axisymmetric Stellarators

by

M.H. Redi, W.A. Cooper, A. Diallo, G-Y. Fu, C. Nuhrenberg, A.H. Reiman, R.B. White, M.C. Zarnstorff and the NCSX Team

July 2000

$\int D \sqrt{D} \int \sqrt{\zeta} \int\left[\begin{array}{l}\text { PAINCETON } \\ \text { PLABMA PHYSICS } \\ \text { LABOAATOAY }\end{array}\right.$

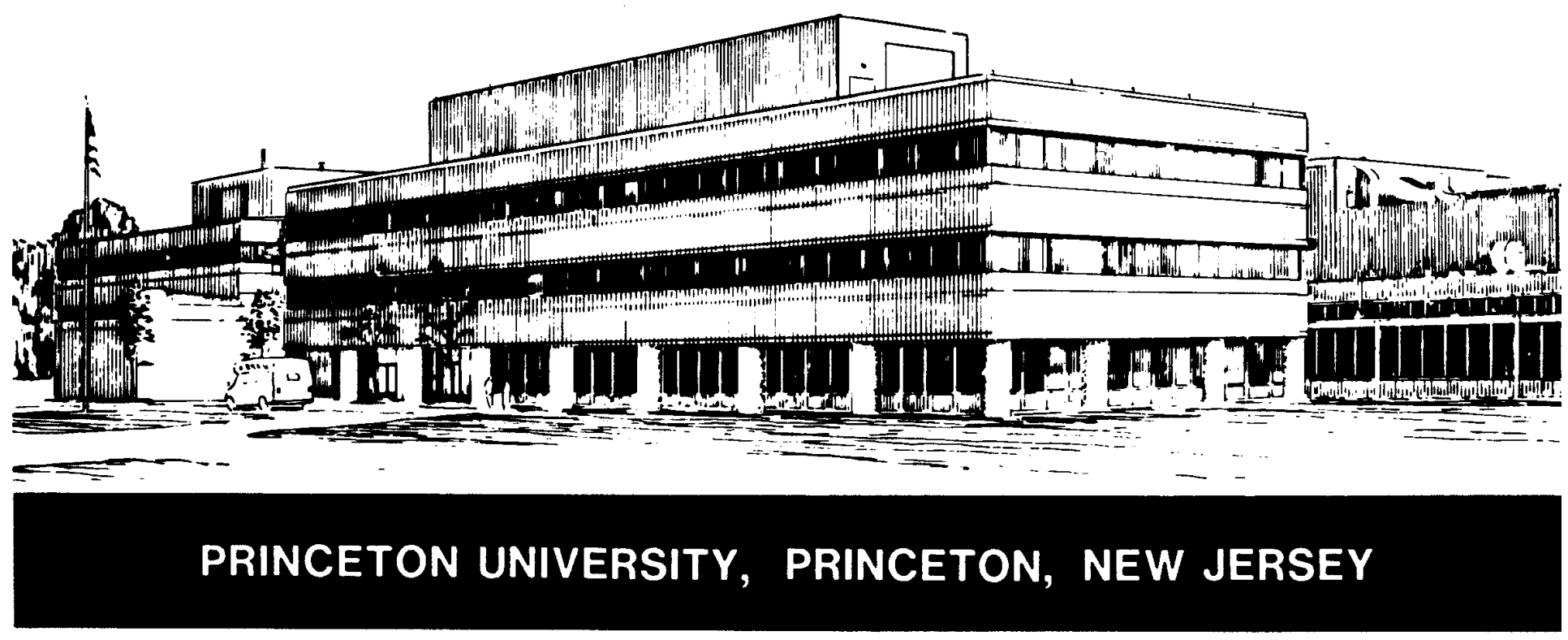




\section{PPPL Reports Disclaimer}

This report was prepared as an account of work sponsored by an agency of the United States Government. Neither the United States Government nor any agency thereof, nor any of their employees, makes any warranty, express or implied, or assumes any legal liability or responsibility for the accuracy, completeness, or usefulness of any information, apparatus, product, or process disclosed, or represents that its use would not infringe privately owned rights. Reference herein to any specific commercial product, process, or service by trade name, trademark, manufacturer, or otherwise, does not necessarily constitute or imply its endorsement, recommendation, or favoring by the United States Government or any agency thereof. The views and opinions of authors expressed herein do not necessarily state or reflect those of the United States Government or any agency thereof.

\section{Availability}

This report is posted on the U.S. Department of Energy's Princeton Plasma Physics Laboratory Publications and Reports web site in Calendar Year 2000. The home page for PPPL Reports and Publications is: http://www.pppl.gov/pub_report/

DOE and DOE Contractors can obtain copies of this report from:

U.S. Department of Energy

Office of Scientific and Technical Information

DOE Technical Information Services (DTIS)

P.O. Box 62

Oak Ridge, TN 37831

Telephone: (865) 576-8401

Fax: (865) 576-5728

Email: reports@adonis.osti.gov

This report is available to the general public from:

National Technical Information Service

U.S. Department of Commerce

5285 Port Royal Road

Springfield, VA 22161

Telephone: $1-800-553-6847$ or

(703) $605-6000$

Fax: (703) 321-8547

Internet: http://www.ntis.gov/ordering.htm 


\title{
Stability and Transport in Compact Quasi-Axisymmetric Stellarators
}

\author{
M. H. Redi ${ }^{1}$, W. A. Cooper ${ }^{2}$, A. Diallo ${ }^{4}$, G-Y. Fu ${ }^{1}$, C. Nührenberg ${ }^{3}$, \\ A. H. Reiman ${ }^{1}$, R. B. White ${ }^{1}$, M. C. Zarnstorff ${ }^{1}$ and the NCSX Team \\ ${ }^{1} P P P L$, Princeton University, Princeton, NJ 08543 \\ ${ }^{2} C R P P-P P B$, Lausanne, Switzerland \\ ${ }^{3} I P P$, Greifswald, Germany \\ ${ }^{4}$ Physics Department, University of Iowa, Iowa City, Iowa 52242
}

\section{Introduction}

The potential performance and flexibility of a compact, quasi-axisymmetric (QAS) stellarator design [1], has been addressed by studying the effects of varied pressure and rotational transform profiles on the global, ideal magnetohydrodynamic (MHD) stability and the energetic particle transport [2]. The CAS3D [3] and TERPSICHORE [4] code packages were used in the MHD studies while the ORBITMN/ORBIT3D [5,7,2] code package was used for the transport simulations of the three field period QAS.

To assess robust performance in a medium-size experiment, the VMEC code [6] was used to obtain magnetic flux surfaces for 30 equilibria near the design point [1], while keeping the boundary shape and the average beta fixed at $3.8 \%$. The plasma equilibria obtained were designated P0X/IOY as follows: P00/I00 was the baseline configuration. P01, P02 and P03 were defined so that P01 was similar to P00, P02 was more peaked than P01, while P03 was broader than P01. P04 was a very broad, parabolic pressure profile and P05 was the pressure profile used in helias reactor studies based on the W7-X design. The iota profiles were chosen as follows: I01 was linear, maintaining $\mathfrak{l}(0)$ and $\mathfrak{t}(\mathrm{a})$ the same as in I00. I02 and I03 were based on I01 and also kept $\mathrm{l}(0)$ and $\mathrm{l}(\mathrm{a})$ as in the baseline case, but with edge shear increased by a factor of 1.5 and 2. I04 was a linear iota profile with $\mathrm{t}(0)$ as for the other profiles, but $\mathrm{l}$ (a) higher than 0.5 , similar to I01. The pressure and iota profiles are shown in Ref. [2].

\section{Stability of the External Kink and Periodicity-Preserving Modes}

Stability calculations for the pressure and iota profile variations were made with TERPSICHORE, with a pseudoplasma approximation for the vacuum region, and a conducting wall at 1.5 minor radii away from the plasma boundary. A range of MHD behaviors was found, with a robust region of stability around the design point (see Fig. 1). The $\mathrm{N}=0$ and $\mathrm{N}=1 \mathrm{MHD}$ modes were destabilized by steep pressure gradients, depending on the iota profile. Figure 1 shows how the stability of the $\mathrm{N}=1$ external kink mode depends on the pressure and iota profiles. For pressure profiles P00 and P04 the unstable modes found were similar for all the iota profiles. Global kink modes were generated by steeply peaked profiles near the half-radius and edge localized kink (ELK) modes were found if the edge iota was above 0.5 and if there was a steep edge pressure gradient. These ELKs in the QAS were driven by high edge current densities.

CAS3D extended TERPSICHORE's calculations to equilibria with no conducting wall. Figure 2 shows the global kink instability as calculated by both TERPSICHORE and CAS3D for P02/I00. Figure 3 shows the CAS3D result for beta above the design point: the marginally unstable $\mathrm{N}=1$ eigenfunction for $\mathrm{P} 00 / \mathrm{I} 00$ at $3.9 \%$ beta for the case where the conducting wall is at infinity, too far away for stabilization. 
Figure 4 shows the destabilization of the kink mode eigenvalue with increasing beta, as calculated by the two MHD stability codes. Here the beta was scaled with increasing toroidal plasma current. The $\mathrm{N}=1$ kink mode is calculated by the CAS3D2.vac module of CAS3D, with a conducting wall at infinity, to be stable below beta approximately $3.9 \%$ (solid circles). TERPSICHORE (open squares), with a conducting wall at $2.5 \mathrm{a}$ from the plasma edge, finds a higher value for the critical value of beta at which the $\mathrm{N}=1$ kink mode remains stable, namely $4.03 \%$. Convergence studies confirm these results. The kink mode is stabilized by a nearby conducting wall for QAS stellarators, as for tokamaks. A simple model is being developed for stabilization of the external kink in QAS.

\section{Energetic Particle Transport}

Neutral beam ion losses for hydrogen beams at $\mathrm{B}=2 \mathrm{~T}$ are $25 \%$ after one slowing down time, using a new complete test particle collision model in ORBIT3D. This is in good agreement with recent calculations [1], and in contrast to our earlier work which used a simpler collision model $[2,7]$. We find little effect on the energetic particle loss from the variations in plasma pressure and iota [2]. Among the different equilibria, the variability in the energetic particle loss was less than $\pm 15 \%$ that of the design point, confirming the robustness of the energetic particle confinement in the QAS plasmas.

\section{Conclusions}

A series of calculations varying pressure and iota profiles for a compact QAS shows that there is stability of the $\mathrm{N}=1$ and $\mathrm{N}=0$ kink mode near the design point, with kink mode destabilization possible, depending on the pressure and iota profiles chosen. These calculations for edge poloidal flux, plasma boundary shape and beta kept constant also demonstrate that many of the concepts of tokamak MHD are useful in understanding how instabilities arise in QAS. The CAS3D and TERPSICHORE codes agree in calculations of the critical beta below which the external kink mode is stabilized. The two codes identify the same poloidal and toroidal harmonics $(m, n)$ and same radial behavior of the largest Fourier components of a global $\mathrm{N}=1$ kink instability when the pressure profile is steep near the plasma half radius, as well as stability for less steep pressure profiles. Good stability is found from both codes which use different models to describe the vacuum plasma and assume different distances between the plasma and the conducting wall.

Energetic particle loss of $25 \%$, with little change when the equilibrium is varied, is acceptable. Robust and flexible performance is found for this compact, quasiaxisymmetric.

We thank R.J. Goldston, R.J. Hawryluk, and G.H. Neilson, Princeton Plasma Physics Laboratory, for encouragement and support. We also thank H. Mynick, N. Pomphrey, J. Manickam and D. Monticello at Princeton Plasma Physics Laboratory, and D. Spong, E. Lazarus and S. Hirshman at Oak Ridge National Laboratory for clarifying discussions.

*Supported by the US Dept. of Energy Contract DE-AC02-76CH03073.

[1] G. H. Neilson, et al., Phys. Plas. 7 (2000) 1911.

[2] M. H. Redi, et al., Phys. Plas. 7 (2000) 2508.

[3] C. Nührenberg, Phys. Plas. 6 (1999) 137. C. Nührenberg, Phys. Plas. 3 (1996) 2401. C. Schwab, Phys. Fluids B5 (1993) 3195.

[4] W. A. Cooper, et al., Phys. Plas. 3 (1996) 275.

[5] R. B. White and M. S. Chance, Phys. Fluids 27 (1984) 2455.

[6] S. P. Hirshman, W. I. Van Rij, P. Merkel, Comput. Phys. Comm. 43 (1986) 143.

[7] M. H. Redi, et al., Phys. Plas. 6 (1999) 3509. 


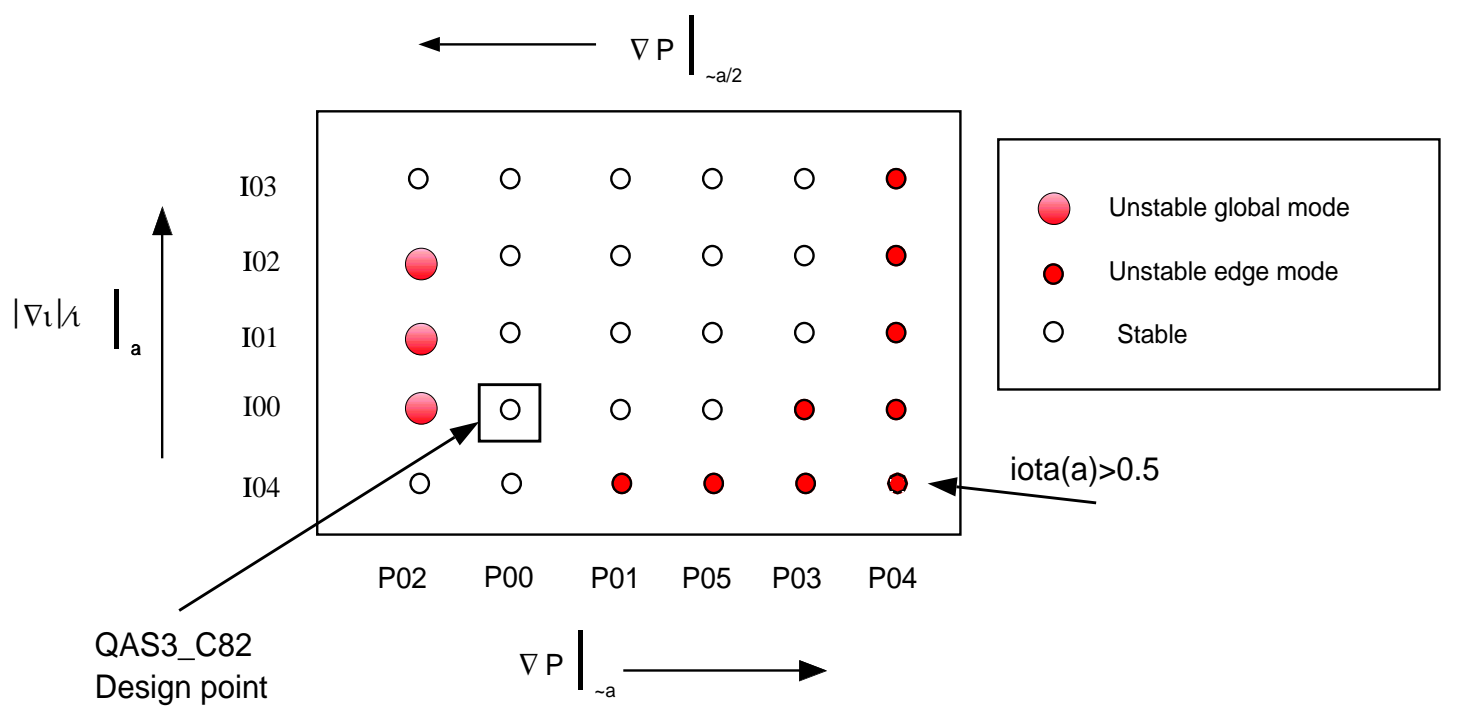

Fig. $1 \mathrm{~N}=1$ family stable and unstable configurations for 30 equilibria. Stability and instability identified by the TERPSICHORE code.
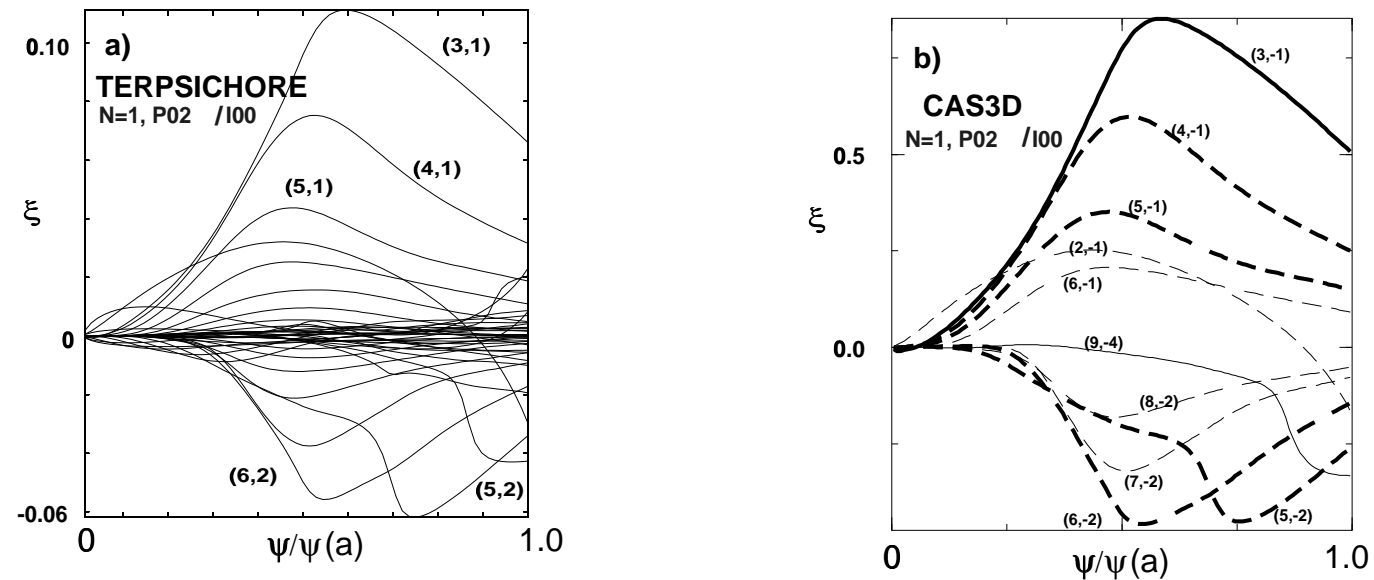

Fig. 2 The unstable external kink mode for P02/I00, 128 flux surfaces, 108 harmonic basis function modes, odd parity perturbation. $\psi / \psi(a)$ is the edge normalized toroidal flux. Shape and identification of largest Fourier components agree in both codes. 

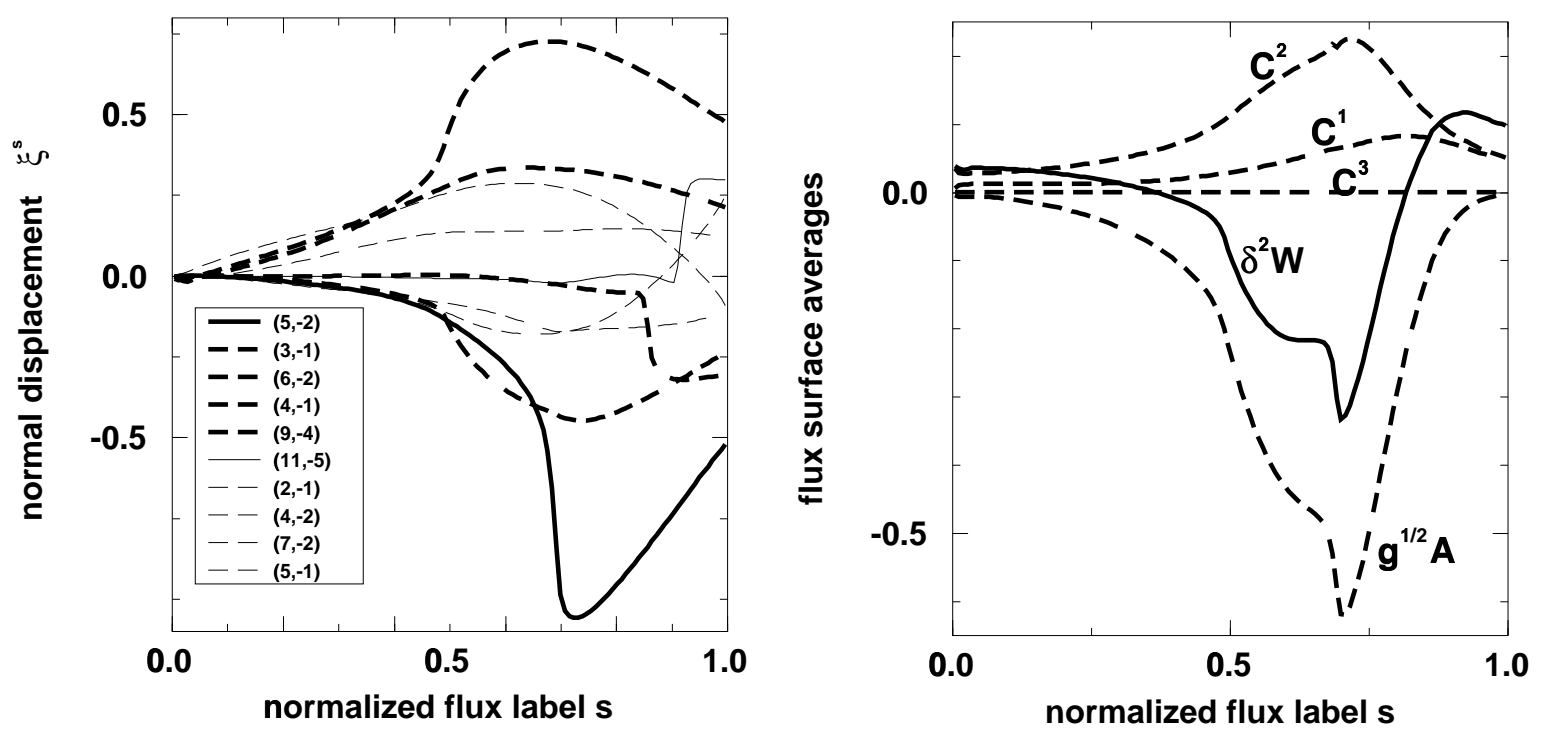

Fig. 3 CAS3D calculations for the external kink mode in the design point case P00/100 above the design point beta, beta $=3.9 \%$,

Left: harmonics of the normal displacment.

Right: balance of terms in the energy integral.

The perturbation is formally unstable, but very close to stabilization.

The influence of divergent parallel current densities at natural resonances (e.g. 3/8) has been eliminated. Computation parameters as in Fig. 1

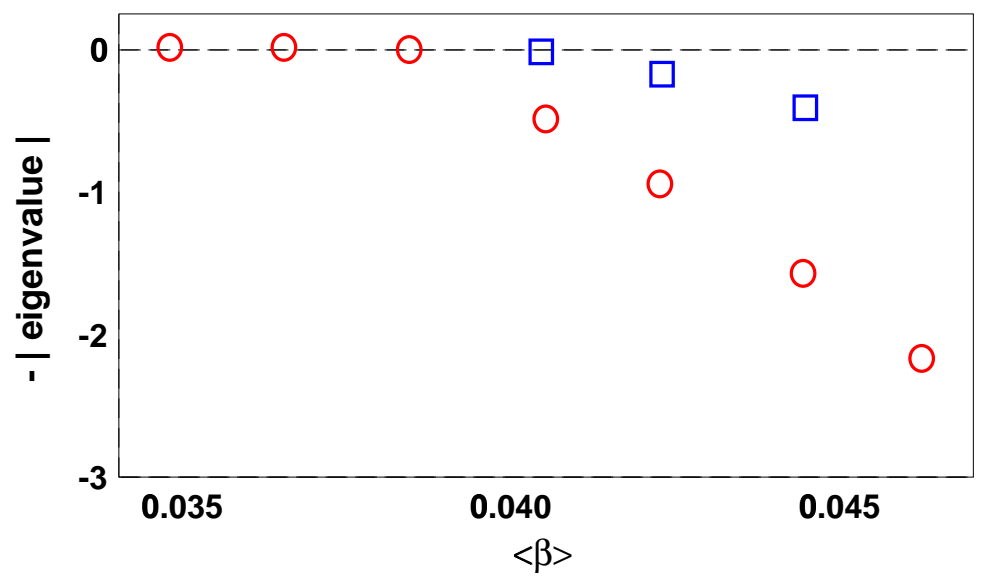

Fig. 4 Calculation of stabilization of $N=1$ external kink mode eigenvalue. Open circles: CAS3D with wall at infinity; stabilization at beta $3.9 \%$. Open squares: TERPSICHORE with wall at 2.5a, marginal beta at $4.03 \%$. Eigenvalues from CAS3D: $\lambda\left(10^{-2}\right)$, from TERPSICHORE $\lambda\left(10^{3}\right)$. 
The Princeton Plasma Physics Laboratory is operated by Princeton University under contract with the U.S. Department of Energy.

\author{
Information Services \\ Princeton Plasma Physics Laboratory \\ P.O. Box 451 \\ Princeton, NJ 08543
}

Phone: 609-243-2750

Fax: 609-243-2751

e-mail: pppl_info@pppl.gov

Internet Address: http://www.pppl.gov 